\title{
A formação da criança leitora por meio dos gêneros do discurso: questões metodológicas
} The formation of a reading child by discourse genres: methodological questions

https://doi.org/10.34112/2317-0972a2020v38n78p79-95

\author{
Edith Maria Batista Ferreira ${ }^{1}$ \\ Joelma Reis Correia ${ }^{2}$
}

RESUMO: Este artigo tem por objetivo discutir a necessidade do ensino do ato de ler ser desenvolvido no espaço da sala de aula com base nos gêneros do discurso, tendo como parâmetro os seus aspectos vitais. Aborda os gêneros do discurso como lócus de manifestação da linguagem, por se originar nas esferas ou campos da atividade humana. Analisa situações vivenciadas em sala de aula que afastam ou aproximam da leitura a criança dos anos iniciais. Conclui que durante a aprendizagem da leitura as crianças precisam ser ensinadas pela porta dos gêneros do discurso para que possam compreender o sentido do ato cultural para responder às suas necessidades na vida.

PALAVRAS-ChAVE: Linguagem escrita; gênero do discurso; ensino do ato de ler.

ABSTRACT: This article's goal is to discuss the need to teach the act of reading as being developed in the classroom environment based on speech genres. The article approaches the speech genres as locus of language manifestation, as it originated in the spheres or fields of human activity. It analyzes situations experienced in classroom that repel or approximate the reading to the children in the begging years. It defends that the act of reading needs to be teached in school throughout speech genre, having as parameters as its vital aspects. It

1. Universidade Federal do Maranhão, São Luís, Maranhão, Brasil.

2. Universidade Federal do Maranhão, São Luís, Maranhão, Brasil. 
concludes that during learning how to read, children need to be teached through the speech genres so they can comprehend the meaning of the cultural act to attend their needs in life. KEYWORDS: Written language; speech genres; teaching the act of reading.

\section{INTRODUÇÃO}

O ensino da leitura sempre foi uma atribuição e um desafio da escola. Ao longo dos tempos a oralidade foi a base do ensino da leitura, cuja aprendizagem, compreendida como uma técnica, constituía-se na transformação das marcas visuais em vibrações sonoras, afinal, ler em voz alta era a competência a ser conquistada (BAJARD, 2014a). Ao conceber leitura como prática de oralização dos textos a ênfase recai na tradução sonora das letras, uma vez que a língua é ensinada como entidade abstrata.

Contrariamente a essa perspectiva, entendemos o ato de ler como atribuição de sentidos ao texto gráfico. Sendo assim, o seu ensino não pode estar apartado das relações humanas, pois são as situações sociais concretas, manifestas em enunciados escritos organizados em gêneros discursivos, que se constituem seu objeto de estudo. Portanto, a escola deveria "[...] ensinar os atos do mundo da vida, os atos de escrever e os atos de ler encharcados de pensamentos do Outro" (BAJARD; ARENA, 2015, p. 260).

As pesquisas que temos desenvolvido ao longo das últimas décadas têm se estruturado a partir desses pressupostos. Sendo assim, neste artigo analisamos situações vivenciadas em sala de aula que afastam ou aproximam a criança dos anos iniciais da leitura. O processo de geração de dados, por meio da observação participante, ocorreu em duas turmas do $1^{\circ}$ ano do ensino fundamental de duas escolas da Rede Pública Municipal de São Luís-MA, em momentos diferentes: a primeira, no ano de 2009, durante o desenvolvimento da pesquisa de doutorado, cuja defesa ocorreu no ano de 2011; a segunda, no ano de 2019, quando tivemos a possibilidade de desenvolver um trabalho com a leitura e a escrita cujo objetivo era ressignificar as práticas com a escrita para que esta fosse vivida como linguagem.

Intentamos discutir a necessidade do ensino do ato de ler ser desenvolvido no espaço da sala de aula com base nos gêneros do discurso, a partir dos estudos de Arena (2008, 2010, 2017), Bakhtin (2016), Bajard (2012, 2014a, 2014b), Jolibert (1994, 2006), Volóchinov (2013) e outros. Para tanto, abordaremos os gêneros enunciativos como lócus de manifestação da linguagem, por se originar nas esferas ou campos 
da atividade humana. Defendemos que o ato de ler precisa ser ensinado na escola a partir dos gêneros do discurso, tendo como parâmetro os seus aspectos vitais.

OS GÊNEROS Do DISCURSO COMO LÓCUS DE MANIFESTAÇÃo DA LINGUAGEM

Embora no espaço escolar a leitura, assim como a escrita, seja considerada objeto de ensino e aprendizagem de professores e alunos, temos percebido, especialmente no contexto em que atuamos, que este objeto cultural não tem recebido o valor e a importância que deveria ter, exatamente por não ser utilizado como linguagem, ou seja, em vez de ser concebido como forma de interação social, o foco ainda tem recaído na língua como um produto morto, imóvel, uma vez que o ensino tem se fixado nas unidades mínimas da língua (o som, a letra, a palavra, a oração).

Nessa perspectiva, em pleno século XXI, a escola ainda insiste em controlar o ato de ler, à medida que não autoriza que a interação verbal, essência efetiva da linguagem, apareça. Portanto, enquanto nas múltiplas atividades humanas as pessoas se afetam umas às outras, suas ações provocam (re)ações em outras (SMOLKA, 2017), ocasionadas pelos enunciados orais e escritos que produzem, o mesmo não se percebe no espaço escolar, visto que as crianças não têm o que dizer, especialmente por não terem a quem dizer.

Sendo assim, corroboramos Arena (2017) quando afirma que o modo de organização da escola tem impedido a relação estreita entre os alunos e a vida, portanto, entre os gêneros e as várias esferas ou campos da atividade humana. Se o emprego da língua se efetua por meio de enunciados (gêneros), $o$ ato de ler como tal somente ganha vida nas relações entre os homens, portanto, não pode ser descolado "do ato humano para ser ensinado, uma vez que é o ato humano de escrever e ler, culturalmente, socialmente e historicamente elaborado que se tornaria o objeto de ensino e de aprendizagem" (ARENA, 2017, p. 18).

É por esse motivo que neste texto situamos a definição de gênero discursivo em sua relação estreita e vital com dois elementos que consideramos essenciais para que $o$ ato de ler seja trabalhado no espaço da sala de aula "pra valer": as esferas ou campos da atividade humana (a situação social concreta) e as relações enunciativas/discursivas.

Como mencionamos anteriormente, geralmente a escola reduz o contato do aluno com a leitura ao simular situações sociais, visto que seu interesse se volta apenas para o aparato técnico que compõe o ato de ler. Com isso, o aluno perde 
a oportunidade de examinar o ato cultural inserido na situação social onde verdadeiramente ele, $o$ ato cultural, nasce.

Deixa-se de compreender, assim, que todo o processo de ensino e aprendizagem da leitura na escola depende, inicialmente, de situar o aluno em relação à situação social de onde o enunciado provém. Por esse motivo, Jolibert (1994), ao falar das competências/conhecimentos linguísticos necessários para a leitura de um texto, traz como primeiro aspecto do trabalho "a noção de contexto", ou seja, para a autora é preciso que o professor esclareça à criança sobre a situação de comunicação, informando-lhe por quais vias concretas um texto chega aos seus olhos, qual a sua origem, se foi extraído de um escrito complexo (jornal, revista infantil, álbum, fichário, livro de contos, ou poemas etc.) ou é um escrito autônomo (carta, cartaz, panfleto etc).

Volóchinov (2013, p. 173) se aproxima da discussão apresentada por Jolibert (1994) ao afirmar:

Tudo nos mostra de maneira bastante convincente o papel importante que tem a situação na criação da enunciação. Se os falantes não estiverem unidos por essa situação, se não tiverem uma compreensão comum do que está ocorrendo e um clara atitude a esse respeito, suas palavras são incompreensíveis, insensatas e inúteis.

Não é por acaso que Bakthin (2016) se dedica, em algumas páginas do seu registro "Os gêneros do discurso", a situar a diferença entre as unidades da língua (a palavra e a oração) e o enunciado, e as implicações do estudo daquelas apartadas da situação social:

Quando se analisa uma oração isolada, destacada do contexto, os vestígios do direcionamento e da influência da resposta antecipável, as ressonâncias dialógicas sobre os enunciados que antecedem aos outros, os vestígios enfraquecidos da alternância dos sujeitos do discurso, que sulcaram de dentro o enunciado, perdem-se, obliteram-se, porque tudo isso é estranho à natureza da oração como unidade da língua (BAKHTIN, 2016, p. 69, grifo nosso).

Observamos que a ausência da situação comunicativa nas unidades da língua impede que as relações enunciativas/discursivas sejam geradas. Como deduz o próprio Bakhtin (2016, p. 68), 
[...] as unidades significativas da língua - a palavra e a oração por sua própria natureza são desprovidas de direcionamento, de endereçamento - não são de ninguém e a ninguém se referem. Ademais, em si mesmas carecem de qualquer relação com o enunciado do outro, com a palavra do outro.

Quando a escola seleciona as unidades da língua em detrimento dos enunciados ou gêneros do discurso, ela inventa, simula o ato de ler, e, nesse caso, como complementa Arena (2017), o objeto ler assume o papel principal em vez do ato humano com ele praticado.

\section{O ATO DE LER PELOS GÊNEROS DO DISCURSO}

Como mencionamos, somente pelos gêneros do discurso a vida entra na língua, aspecto que precisa ser considerado quando pensamos o ato de ler na escola. Portanto, os textos (materialidade dos gêneros) usados para esse fim não podem ser escolhidos a priori, mas será a situação da vida que determinará a relação discursiva pelo ato de ler. Nesse sentido, fica clara a posição enunciativa do aluno, ou seja, ele vai ler sempre para responder a um interesse imediato, como:

- $\quad$ [...] à necessidade de viver com os outros, na sala de aula e na escola;

- para se comunicar com o exterior;

- para descobrir as informações das quais necessita;

- para fazer (brincar, construir, levar a termo um projeto-empreendimento);

- para alimentar o imaginário;

- para documentar-se no quadro de uma pesquisa em andamento. (JOLIBERT, 1994, p. 31)

Desse modo, as situações de ler para valer são garantidas na escola porque, além dos alunos terem acesso a diferentes práticas discursivas, terão a possibilidade de dizer a sua intenção discursiva, definida por Bakhtin (2016) como projeto de dizer, e, ao mesmo tempo, terão acesso à intenção discursiva dos seus interlocutores, contemplando nesse processo as relações enunciativas. Volóchinov (2013, p. 164) sinaliza o que acontece quando o ato de ler é destituído dessa relação: 
O orador que escuta somente sua voz, ou o professor que vê somente seu manuscrito, é um mau orador, um mau professor. Eles mesmos paralisam a forma de suas enunciações, destroem o vínculo vivo, dialógico, com seu auditório e com isso tornam sem valor sua intervenção.

Se destituímos o ato de ler desse intercâmbio verbal, o gênero se transforma apenas em uma categoria, em uma forma fixa, cuja metodologia tem como propósito a identificação dos traços característicos que mais predominam e marcam um texto, a extração das ideias do autor, a conferência de letras, sílabas e palavras, a leitura oral, cuja intenção é apenas verificar se o aluno realiza com tranquilidade a emissão sonora das palavras.

Levantar críticas à forma fixa com que muitas vezes o gênero é trabalhado na escola não significa dizer que não se deve examinar a forma da enunciação, pois, segundo Volóchinov (2013, p. 175), "o conteúdo e o significado de uma enunciação necessitam de uma forma que os realize, que os efetue, pois fora de tal forma eles sequer existiriam". No entanto, como esclarece Sobral (2011), "forma", na perspectiva do gênero do discurso, está relacionada à ação autoral, portanto, sujeita a variações conforme o projeto de dizer do autor e as mudanças históricas e sociais, logo, não é algo dado nem estático. Por esse motivo, o gênero do discurso é definido por Bakhtin (2016, p. 12) como "tipos relativamente estáveis de enunciados", pois ele exige que se respeite certas particularidades, mas permite alterações para atender a situação social imediata, bem como o projeto enunciativo do autor.

Embora a definição de gênero em Bakhtin descarte uma classificação rígida deste, como apresentado nos livros didáticos ou gramáticas, enquanto atividades estáveis eles são constituídos pelos seguintes elementos: conteúdo temático, construção composicional e ato estilístico. De acordo com Sobral (2011, p. 42), é preciso evitar olhar para esses três elementos separando-os, "uma vez que eles existem integradamente nos textos, e o uso de três categorias é meramente didático".

No ensino do ato de ler, esses três elementos contribuem para que o professor ensine aos alunos os propósitos comunicativos do texto e o projeto enunciativo de quem o escreveu. O conteúdo temático, por exemplo, está relacionado aos atos humanos e surge na cadeia da comunicação discursiva, portanto, está intimamente ligado à situação social ou extraverbal e, consequentemente, às relações enunciativas. Ao buscarmos as contribuições de Jolibert (1994) para essa discussão, verificamos que tanto a noção de contexto, como os principais parâmetros da situação 
de comunicação (Quem escreveu? Para quem? Para quê? Como isso se manifesta? Onde?) são elementos definidores do tema, o que vai implicar na seleção do texto a ser trabalhado com os alunos.

A composição se refere à forma arquitetônica do texto, ou seja, ao modo de organizá-lo, determinado pelo projeto de dizer do falante. Em Jolibert (1994), esse elemento se materializa quando a autora propõe que seja ensinada aos alunos a superestrutura do texto, que se manifesta sob a forma:

- de organização espacial e lógica dos blocos de texto ("silhueta");

- de esquema narrativo tratando-se de uma "história" (conto, lenda, novela ou romance);

- da dinâmica interna (abertura/encerramento e progressão de um ao outro). (JOLIBERT, 1994, p. 143).

Por fim, o estilo diz respeito ao modo específico do texto apresentar o conteúdo, de organizar o discurso. Esse elemento possibilita a quem lê descobrir o projeto enunciativo de quem produziu o discurso e, nesse processo, inserir-se também no texto. Pelo ato estilístico é possível identificar quais os meios linguísticos, lexicais, fraseológicos e gramaticais presentes no texto, os quais, dependendo da situação social concreta, podem refletir ou não, em maior ou menor proporção, a individualidade do falante na linguagem do enunciado, materializada na

seleção da palavra mais adequada à correlação social existente entre o falante e o ouvinte, palavra que leva em conta minuciosa e precisamente todos os detalhes da pessoa social do interlocutor, sua posição econômica, sua classe, sua posição social etc. (VOLÓCHINOV, 2013, p. 177).

De acordo com Jolibert (1994), um leitor competente é capaz de identificar o estilo do autor do texto. Para tanto, ela considera necessário o trabalho em sala de aula com a linguística textual, a linguística da frase e palavras e microestrutura que as constituem.

Esses três elementos característicos do enunciado (conteúdo, composição e estilo) nos fazem compreender que o ensino do ato de ler precisa partir sempre do gênero do discurso, cujo traço fundamental é o diálogo entre os homens, pois são estas categorias, cada uma com uma função específica, que indicam que "o gênero que 
agasalha os enunciados escritos constitui-se fundamentalmente de componentes materiais ou imateriais que não podem ser desprezados em sua análise, nem em seu ensino, porque são eles as unidades constitutivas de um todo" (ARENA, 2017, p. 20).

Desse modo, não se justifica o ensino do ato de ler com ênfase na oralidade ou nos aspectos mínimos da língua, ou seja, à margem das condições sócio-culturais de sua criação, visto que na vida esse ato cultural só faz sentido para que o eu e o outro possam estabelecer uma relação enunciativa, conforme os interesses e necessidades de cada um.

Nesse sentido, na próxima seção problematizamos algumas situações de sala de aula, com crianças do $1^{\circ}$ ano do Ensino Fundamental em duas escolas da Rede Pública Municipal de São Luís. A metodologia utilizada em sala de aula pode aproximá-las ou afastá-las desse ato cultural que éler, especialmente ao se considerar ou não seu acesso aos gêneros do discurso.

APRENDER A LER POR MEIO DOS GÊNEROS DO DisCURSO: EM BUSCA DO SOM DO SENTIDO DA PALAVRA

Reconhecendo que à escola coube historicamente a responsabilidade de formar leitores e produtores de textos, neste trabalho problematizamos o ensino da leitura, muito embora reconheçamos o entrelaçamento desses dois movimentos no processo de apropriação da língua escrita. Para fazê-lo, consideramos necessário discutir o que entendemos por leitura.

Recorrendo à memória arriscamos dizer que temos como lembranças do processo de aprender a ler a prática da leitura em voz alta. Aquela em que o professor solicitava a oralização do que estava escrito, em um exercício no qual um aluno iniciava a leitura para que o outro desse continuidade, ou ainda da "leitura de pé de mesa”, em que as crianças, uma a uma, eram chamadas para recitarem para o/a professor/a o texto impresso que estava sobre sua mesa, muito provavelmente presente no livro didático. Ler, nesse sentido, significava decodificar, transpor os signos orais em signos escritos (BAJARD, 2014a) e a leitura em voz alta era o meio pelo qual se constatava o desenvolvimento dessa habilidade.

Muito embora esta prática possa ser situada há algumas décadas atrás, ela ainda é bem presente em nossas escolas, conforme podemos ver na cena descrita durante a pesquisa de doutorado realizada durante o ano de 2009: 
Por volta das 14 horas chego à escola, momento em que a professora sai na porta da sua sala e solicita ao professor de Educação Física, que se encontra no pátio aguardando o horário da sua aula, que venha até a sua turma. [...] Assim que ele aparece na porta, ela diz para os alunos: "Ouviram, crianças, eu não disse que o professor vinha para ver vocês lendo, agora vocês precisam mostrar que sabem ler." E continua: "Sabe, professor, todos os alunos dessa sala já sabem ler. Quer ver?”. O professor entende a situação simulada pela professora e fala: “Ah, eu quero ver sim. Será mesmo?” A professora lhe responde: "Vou lhe provar". Durante o diálogo, as crianças se entreolham e começam a sorrir. Logo após, a professora pergunta para a turma: "Crianças, quem sabe ler aqui?” Todas as crianças levantam o braço e respondem: "eu tia”. Entretanto, algumas delas repreendiam alguns dos seus colegas: "Tu nem sabe ler". A professora, ouvindo esses comentários fala: "Quem ainda não sabe ler está aprendendo", e vira-se para a aluna A e pergunta: “Não é A!”. [...] Logo após, pergunta quem quer vir à frente fazer a leitura de uma música junina registrada numa folha de papel, presa no quadro utilizado para esse fim. Todas as crianças levantam a mão. A professora chama o aluno L., que levanta todo contente. Antes que o aluno comece a fazer o que lhe fora designado, o professor comenta: “Ah, L. não sabe ler não". O aluno logo responde: "sei sim”. A Professora também acrescenta: “Sabe! L sabe ler, professor!”. De imediato, o aluno começa a oralizar o texto. Assim que termina, a professora comenta: "Uma salva de palmas para L gente”. [...] Na seqüência, chama o aluno C. M., que começa a pronunciar bem devagar e de forma tímida as sílabas de cada palavra. A professora pergunta que palavra forma e começa a oralizar juntamente com o aluno. Ao término, comenta: "Viu professor, como C. M. tá quase lendo”. Parabeniza a criança e solicita para ele também palmas. [...]. (Diário de Campo, 16.06.2009).

O episódio acima evidencia uma concepção de leitura expressa na forma como a situação didática foi conduzida: ler é decodificar, transformar letras em sons. A forma como a proposta foi organizada pela professora não proporcionou às crianças experienciarem o ato de ler como atribuição de sentido (ARENA, 2007), uma vez que a intenção era apenas oralizar o texto para identificação das crianças que "liam” e das que "não liam”. Vemos que a oralização feita não permitiu a atribuição de sentido, mas apenas a emissão sonora das palavras.

O professor de Educação Física apontado na cena poderia ter sido considerado o outro em potencial se a professora o chamasse em sua sala para que as crianças pudessem informar-lhe, a partir da leitura, sobre uma notícia, a divulgação de um 
evento junino, a recitação de uma poesia, o que de fato se configuraria como um ato de locução ou transmissão vocal, ou mesmo para que o próprio professor lesse para os alunos. No entanto, sua participação foi apenas para constatar um processo de avaliação de leitura em que a aprendizagem em jogo era a sonorização/decifração do texto.

Apoiadas em Bajard (2014a), podemos afirmar que a emissão vocal não pode ser confundida com o ato de ler propriamente dito, aquele produtor de sentido, visto que a primeira é exterior à leitura e seu objetivo é a comunicação, não a elaboração de sentido. Nem tampouco pode levar à expectativa de que a escuta do texto, por si só, acarretará automaticamente em habilidades de leitura.

Segundo nossa compreensão, "ler é a ação de atribuir sentido por meio de sinais gráficos, em situações elaboradas pela cultura humana” (ARENA, 2008, p. 132). Os textos, objeto da leitura, são enunciados escritos expressos em gêneros do discurso que emergem das relações dialógicas decorrentes de situações sociais.

Assim, o ato de ler, isto é, o modo como o leitor/a age sobre o texto, precisa ser desenvolvido por meio das relações com os gêneros enunciativos (ARENA, 2017). Isso significa dizer que é necessário criar condições para que o diálogo se estabeleça entre o/a leitor/a e o/a autor/a do texto, efetivado na construção de sentidos.

O sentido nunca está dado a priori, é construído na relação dialógica entre os discursos e os interlocutores, por meio da compreensão gráfica do texto; por isso, a aprendizagem do ato de ler é processo que implica a busca do som do sentido da palavra, e não a decodificação. É um ato solitário, que exige procedimentos de leitura que almejam a compreensão do texto gráfico, não no que diz respeito ao encadeamento das letras, mas ao código ideográfico mais amplo.

Embora a leitura seja ato solitário, porque exige que o sujeito se debruce sobre o enunciado escrito, acionando operações cognitivas complexas, as relações dialógicas não desaparecem. É bem verdade que o/a ouvinte não existe fisicamente e que $\mathrm{o} / \mathrm{a}$ locutor/a está sozinho, mas o/a leitor/a permanece construindo enunciações em segredo. Volóchinov (2016, p. 164) exemplifica esse processo dialógico de construção de enunciações íntimas quando afirma:

De fato, assim que começamos a refletir sobre um problema, assim que começamos a examiná-lo com atenção, de imediato nosso discurso interno - às vezes pronunciado em voz alta - toma a forma de pergunta e resposta, de afirmação e de sucessivas negações. 
$\mathrm{O}$ autor se refere à resolução de problemas, contudo, será que processo semelhante não é vivido quando fazemos a leitura silenciosa? Quando buscamos compreender o texto escrito? Acaso não dialogamos com o/a autor/a, concordando, discordando, ampliando o que foi dito durante o ato de ler, fazendo perguntas e buscando respostas? Jolibert corrobora essa ideia: "se ler é interrogar um texto em função de um contexto, de um propósito, de um projeto, para dar resposta a uma necessidade, então corresponde a uma interação ativa, curiosa, ávida, direta entre leitor e texto" (2006, p. 54).

Nesse processo dialógico de atribuir sentido ao enunciado escrito, como ratificou a autora, assumimos uma posição responsiva e este deve ser o horizonte a ser alcançado pela escola no ensino do ato de ler. Nesse sentido, o ponto de partida deve estar nas situações sociais que criam enunciados escritos que se organizam em gêneros discursivos (BAKHTIN, 2016).

O episódio narrado a seguir nos ajudará a enxergar esse movimento responsivo presente no ato de ler. Ele foi vivido em uma escola da rede pública municipal de São Luís-MA, em uma turma de primeiro ano do ensino fundamental, durante o processo de pesquisa realizado nos anos de 2018 e 2019, cujo objetivo era ressignificar as práticas de ensino da escrita para que esta fosse vivida como linguagem.

O processo de observação, realizado uma vez por semana, revelou que as práticas de escrita oportunizadas às crianças do primeiro ano tinham o foco exclusivo no reconhecimento de letras e na correspondência letra-som, sendo destituídas de sentido. Era necessário, portanto, criar oportunidades para que as crianças lessem verdadeiramente e se apropriassem do sistema de escrita, visto que a proposta era viver a pesquisa-ação. Nesse tipo de pesquisa "os pesquisadores desempenham um papel ativo no equacionamento dos problemas encontrados, no acompanhamento e na avaliação das ações desencadeadas" (THIOLLENT, 1988, p. 15).

Desse modo, buscando incidir diretamente no ensino da escrita como linguagem, fomos criando oportunidades para que as crianças sentissem necessidades reais de expressão e de comunicação, utilizando-se para isso da escrita. Para tanto, foi feita inicialmente a mediação de leitura do livro $O$ domador de monstros, de Ana Maria Machado, abrindo espaço para uma rica roda de conversa em que as crianças falaram sobre os monstros que habitam o universo infantil. Além dos monstros imaginários, de animais ferozes, a Momo, uma boneca assustadora inspirada na escultura criada pelo japonês Keisuke Aiso, que aparece para as crianças durante a exibição de vídeos do YouTube Kids ensinando práticas de suicídio, homicídio e formas de mutilação, 
tomou grande parte da conversa. Além de exporem seus medos, foram discutindo formas de "domar a Momo", contando, principalmente, com a participação do adulto. Desenharam ainda monstros imaginários e escreveram suas características.

O trabalho com a literatura acompanhou todo o percurso da pesquisa, uma vez que acreditamos que esta rica manifestação cultural amplia e transcende a experiência do leitor, como aconteceu com a discussão sobre os monstros e os medos infantis, além de ser uma excelente oportunidade de iniciação da criança no mundo da cultura escrita (ARENA, 2010). Enquanto gênero discursivo, a literatura favorece as relações interlocutivas.

Depois disso, nova conversa emergiu sobre os animais ferozes e aqueles bem esquisitos, ao discutirmos o projeto a ser desenvolvido no semestre letivo. Foi quando a aluna A. L. propôs estudarmos os animais exóticos. Após explorar o sentido da expressão "exóticos", as crianças foram apresentando seus conhecimentos e curiosidades sobre os animais e a temática foi aprovada por todos, apresentando-se como muito significativa para ser objeto de estudo. Definido o tema do projeto, fomos planejar coletivamente sua execução: quais animais estudar, o que saber sobre eles e onde pesquisar, transformando tudo isso em boas situações didáticas para o ensino e a aprendizagem do ato de ler.

A opção de ensinar por meio de projetos se justifica pelo fato de eles conferirem sentido à presença das crianças na escola, provocarem uma revisão profunda nas relações entre adulto e criança e favorecerem uma aprendizagem com sentido (JOLIBERT, 1994). Esses pressupostos orientaram a construção do projeto de leitura "Animais Exóticos". Como vimos, sua existência emergiu de uma situação social concreta mobilizadora de relações enunciativas entre as crianças para o desenvolvimento do ato de ler.

A definição dos animais exóticos a serem estudados aconteceu a partir da atividade "A bicharada está solta!". Na biblioteca foi organizado um tapete contendo imagens de animais pouco comuns existentes em algumas partes do mundo. As crianças foram conduzidas ao local. Chegando lá, a porta estava fechada e a senha para a entrada era ler o cartaz que continha a oração: A BICHARADA ESTÁ SOLTA! As crianças foram buscando pistas para ler o que estava escrito e, ao descobrirem, a porta foi aberta, depois de muito suspense. Ao entrarem na sala foram observando as imagens e lendo as legendas, para identificação dos bichos. Dos animais existentes, foram definidos nove animais exóticos para estudo: Dragão Azul, Diabo Espinhoso, 
Dragão Marinho Folhado, Guepardo, Porco do Mar, Peixe Espinhoso, Centopeia Gigante, Macaco Narigudo e Feneco.

Acreditamos que para aprender a ler é preciso se estar envolvido/a pelos/com os escritos, ter razões verdadeiras para ler, interrogar o texto e mobilizar conhecimentos para responder às perguntas advindas das relações interlocutivas estabelecidas entre leitor/a e autor/a. Assim, as atividades de leitura foram pensadas a partir da situação social definida, qual seja, aprender sobre os animais exóticos. Nesse sentido, foram selecionados textos e outros materiais que favorecessem o acesso à informação sobre esses animais. $\mathrm{O}$ ato cultural de ler textos expositivos a ser aprendido exigiu atenção para os modos e funções que esses enunciados assumem nas esferas da vida. Era preciso ensinar às crianças como lemos esse tipo de texto.

Considerando a natureza desse gênero, os textos expositivos são lidos com o propósito de aprender sobre determinado assunto, portanto, é necessário ter clareza quanto aos objetivos antes de iniciar a leitura. $\mathrm{O} / \mathrm{A}$ leitor/a adota procedimentos importantes, tais como: sublinhar informações relevantes, identificar palavras e expressões desconhecidas, fazer resumos (SOLÉ, 1998); esses procedimentos foram objeto de aprendizagem ao longo do projeto.

No estudo sobre o Dragão Azul, o texto expositivo foi copiado em cartolina para que o mesmo pudesse ser trabalhado no coletivo. Inicialmente ele foi afixado na parede da sala e foi pedido às crianças que fizessem a leitura silenciosa e individual, buscando uma aproximação global com o mesmo por meio de indícios (contexto, situação comunicativa, tipo de texto, silhueta...) que funcionaram como pistas para o ato de ler.

Bajard (2012, p. 221) denomina esse movimento de "descoberta do texto"; diz que ele "convoca os saberes do aprendiz (sua intuição, sua sensibilidade), mas também seu poder de fazer analogias, inferências e deduções". Nesse processo de descoberta os aspectos gráficos do texto foram explorados, por meio da identificação do título, de reconhecimento dos parágrafos, de letras maiúsculas, de espaços entre palavras, desvelando assim sua forma.

Depois da interação coletiva com o texto e da partilha das impressões, ele foi entregue impresso, para que individualmente as crianças fizessem uma segunda leitura, agora interrogando-o a partir da lista de perguntas que tratavam de informações sobre a vida do animal: alimentação, habitat, tamanho, reprodução, entre outras. Afinal, para começar a ler um texto é preciso criar expectativas sobre o que ele trata e buscar respostas a essas expectativas no próprio texto. 
Os saberes e não-saberes sobre o sistema de escrita foram se evidenciando e demandando o estudo dos microaspectos da língua, momento fundamental no processo de aprender o ato de ler. Como disseram Jolibert e seus colaboradores (2006, p. 187), "as crianças também têm que conseguir identificar as letras e entender como se articulam entre si em um sistema para gerar múltiplas palavras". Contudo, elas não devem ser ensinadas de maneira isolada, descontextualizada, e muito menos antes de se dar a compreensão do texto.

Durante a descoberta do texto, algumas palavras ficavam em evidência e estas eram exploradas em sua forma escrita com intervenções no quadro branco. Entretanto, outras atividades foram propostas com o objetivo de refletir sobre os microaspectos da língua: caça de palavras no texto com critérios estabelecidos pelas crianças (letra inicial e final, quantidade de letras...), reconhecimento de nomes de animais e outras informações no texto, construção da ficha do bicho, colocando as informações (nome, alimentação...) no local adequado etc.

Como vimos, a proposta priorizou ler textos verdadeiros, em seus suportes reais (revistas, livros, internet), utilizando-se de procedimentos praticados nos atos de leitura existentes na vida. Esses encaminhamentos permitiram o desenvolvimento de um léxico de atividades reflexivas sobre as estratégias aplicadas para resolver os problemas levantados pelos textos expositivos (FOUCAMBERT, 1994), além de promover rica aprendizagem sobre o sistema de escrita.

\section{CONSIDERAÇÕES FINAIS}

Como sabemos, é histórica a discussão sobre a melhor maneira de ensinar o ato de ler. Portanto, o que problematizamos neste texto pode não ser novidade para aqueles que têm se debruçado sobre a temática em questão. No entanto, entrar nessa discussão se torna para nós crucial, pois, conforme a localidade geográfica em que nos encontramos, o povo que dela faz parte ainda padece de frágeis situações de acesso à leitura. Na verdade, discutir o ensino do ato de ler na perspectiva apresentada neste texto só faz sentido porque estamos imersas em uma situação concreta e, a partir das relações enunciativas com nossos interlocutores, consideramos ser este um tema necessário para o desenvolvimento de pesquisas.

O primeiro episódio de sala de aula apresentado demonstra bem o que estamos falando, pois embora seja uma situação de pesquisa gerada no ano de 2009, é ainda muito frequente a presença de momentos como os aqui relatados em turmas de 
alfabetização na região geográfica onde estamos situadas. Portanto, consideramos pertinente fazer uso das palavras de Arena, quando afirma que o tema da leitura pode não ser novo, mas também não envelhece, pois é "recorrente, persistente, incômodo, porque atravessa a história" (2007, p. 1).

Sendo assim, temos percebido que ensinar o ato de ler na escola ainda é uma problemática no espaço da sala de aula, porque nos parece não ser compreensível para os/as professores/as que, desde o início do processo, as crianças precisam se aproximar de situações que envolvem o ato de ler pela porta dos gêneros do discurso, o que requer estarmos atentos para todas as situações sociais em que elas estão inseridas. Isso somente é possível quando permitimos que os alunos se coloquem na posição de quem fala e, mais do que isso, que o seu projeto de dizer esteja direcionado a interlocutores reais.

Consideramos este momento crucial para que o ensino do ato de ler faça sentido para as crianças e elas consigam compreendê-lo como um ato humano e profundamente dialógico, já que fazemos uso dele nas relações que estabelecemos com os outros. Nesse processo de aprender o ato, os gêneros do discurso precisam entrar no espaço da sala de aula, materializados em forma de textos, e para compreendê-los se faz necessário lançar o olhar para os elementos que o sustentam: o tema, a composição e o estilo.

Aprofundar o olhar para esses elementos é importante para que a criança tenha acesso ao gênero em termos de recursos de linguagem; porém, do ponto de vista enunciativo. A experiência com as crianças do primeiro ano do ensino fundamental da segunda escola pesquisada tem nos revelado que, de fato, esse pode ser o caminho para aproximá-las do ato cultural de ler e, mais do que isso, levá-las a perceberem a necessidade desse ato para as suas vidas.

\section{REFERÊNCIAS}

ARENA, D. B. Relações entre ler e fazer locução no ensino fundamental. In: CONGRESSO DE LEITURA DO BRASIL, 16., 2007, Campinas. Anais... Campinas, SP, 2007. Disponível em: http:// www.alb.com.br/anais16. Acesso em: 21 maio 2010.

ARENA, D. B. O ensino da ação de ler e suas contradições. Ensino Em-Revista, Uberlândia, v. 17, n. 1, jan./jun. 2010, p. 237-246.

ARENA, D. B. Dilemas didáticos no ensino do ato de ler. In: I CONGRESO LATINO AMERICANO DE COMPRESION LECTORA, 1., 2008. Anais v. 1... Huancayo, Peru: Universidad del Centro de Peru, 2008. p. 129-136. 
ARENA, D. B. Considerações em torno do objeto a ser ensinado: língua, linguagem escrita e atos culturais de ler e de escrever. In: MORAES, Denise Rosana da Silva; GUIZZO, Antonio Rediver (Org.). Coletânea de artigos: humidades nas fronteiras: imaginários e culturas latino-americanas. Foz do Iguaçu: UNILA/UNIOESTE, 2017. p. 13-28.

BAJARD, Élie. Da escuta de textos à leitura. São Paulo: Cortez, 2014a.

BAJARD, Élie. Ler e dizer: compreensão e comunicação do texto escrito. São Paulo: Cortez, 2014b. BAJARD, Élie. A descoberta da língua escrita. São Paulo: Cortez, 2012.

BAJARD, Élie; ARENA, Dagoberto Buim. Metodologias de ensino - por uma aprendizagem do ato de ler e do ato de escrever em um sistema tipográfico. In: DAVID, Célia Maria. Desafios contemporâneos da educação. São Paulo: Cultura Acadêmica, 2015. p. 251-276.

BAKHTIN, Mikhail. Os gêneros do discurso. São Paulo: Editora 34, 2016.

FOUCAMBERT, Jean. A leitura em questão. Porto Alegre: Artes Médicas, 1994.

JOLIBERT, Josette et al. Formando crianças leitoras. Trad. Bruno Charles Magne. Porto Alegre: Artmed, 1994.

JOLIBERT, Josette et al. Além dos muros da escola: a escrita como ponte entre alunos e comunidade. Porto Alegre: ArtMed, 2006.

SOBRAL, Adail. Gêneros discursivos, posição enunciativa e dilemas da transposição didática. Revista Letras de Hoje, Porto Alegre, v. 46, n. 1, p. 37-45, jan./mar. 2011.

SOLÉ, Isabel. Estratégias de leitura. Porto Alegre: ArtMed, 1998.

SMOLKA, Ana Luisa Bustamante. Da alfabetização como processo discursivo: os espaços de elaboração nas relações de ensino. In: GOULART, Cecília M. A.; GONTIJO, Cláudia Maria Mendes; FERREIRA, Norma Sandra de A. (Org.). A alfabetização como processo discursivo: 30 anos de A criança na fase inicial da escrita. São Paulo: Cortez, 2017

THIOLENT, M. Metodologia da pesquisa-ação. 4. ed. São Paulo: Cortez, 1988.

VOLOCHÍNOV, Valentin Nikolaevich. A construção da enunciação e outros ensaios. Trad. João Wanderley Geraldi. São Carlos: Pedro \& João Editores, 2013.

\section{SOBRE AS AUTORAS}

Edith Maria Batista Ferreira é graduada em Pedagogia (Universidade Federal do Maranhão), tem Mestrado em Educação (Universidade Federal do Maranhão). É professora/pesquisadora da Universidade Federal do Maranhão. Tem experiência na área de Educação, com pesquisa nos seguintes temas: alfabetização; leitura e escrita nos anos iniciais do Ensino Fundamental e Educação Infantil; formação de professores; educação infantil. É vice líder do Grupo de Estudos e Pesquisa "O Ensino da Leitura e da escrita como Processos Dialógicos” e coordena o Projeto de Extensão "Entrelinhas: alfabetização dialógica".

E-mail: edithribeiro75@gmail.com. 
Joelma Reis Correia é graduada em Pedagogia (Universidade Federal do Maranhão), tem Mestrado em Educação (Universidade Estadual Paulista "Julio de Mesquita Filho") e Doutorado em Educação (Universidade Estadual Paulista "Julio de Mesquita Filho"). É professor/pesquisador(a) da Universidade Federal do Maranhão. Tem experiência na área de Educação, com pesquisa nos seguintes temas: alfabetização, leitura e escrita nos anos iniciais do Ensino Fundamental. É líder do Grupo de Estudos e Pesquisa "O Ensino da Leitura e da escrita como Processos Dialógicos” e coordena o Projeto de Extensão "Entrelinhas: alfabetização dialógica”. E-mail: joelmaalfabetiza@gmail.com.

Recebido em 02 de agosto de 2019 e aprovado em 25 de novembro de 2019. 